\title{
ENTREVISTA AL DOCTOR FERNANDO CABIESES (76 AÑOS), MÉDICO NEUROCIRUJANO Y ANTROPÓLOGO
}

\author{
Al estudiar la historia viva te das cuenta que hay todo un sistema \\ de pensamiento llamado 'medicina tradicional' (Cabieses 1995)
}

\section{Pablo Marcos Espinoza Concha ${ }^{1}$ y Paola Soledad Lagos Labbé ${ }^{2}$}

Esta entrevista fue realizada en Valdivia durante el Segundo Congreso Chileno de Antropología, celebrado en la Universidad Austral de Chile en 1995. Luego de buscarlo por varios hoteles, encontramos a Fernando Cabieses Molina (Mérida, Yucatán, México, abril 20 de 1920) después de su desayuno en la Casa de Ejercicios del obispado católico. En un principio se negó a la conversación, quería estar tranquilo para disfrutar de la naturaleza sureña y contemplar la profundidad de un río navegable. Ante nuestra insistencia nos invitó a caminar hasta el Muelle Schuster: "Crucemos el puente, quiero grabar esos pelícanos que llaman tanto mi atención", afirmó. Con su filmadora al cuello, nos introdujo en su mundo, en el que como rieles del ferrocarril viajaban en paralelo la medicina y las 'plantas mágicas'.

Mientras recorríamos las calles de la Isla Teja, comentó lo bien que se sentía en Chile, de la larga amistad que mantenía con algunos chamanes del Perú, de ritos presentes en nuestra vida cotidiana y sobre Amanita muscaria, que queríamos conocer de boca de un especialista de nivel mundial. Con actitud de abuelo protector nos abrazó con la ternura de sus conocimientos y nos regaló una mañana llena de sabiduría.

A más de un año de su fallecimiento (Lima, Perú, martes 13 de enero de 2009), y a quince de la realización de esta entrevista, pretendemos cumplir nuestro rol. Primero, hacer justicia con nuestro personaje, toda vez que el tiempo hace lo suyo: olvida, y, segundo, rendir homenaje al Dr. Fernando Cabieses Molina, un científico 'americanista' que nos obsequió parte de su saber con la humildad de los grandes.
Fundador de las Universidades Cayetano Heredia y Científica del Sur, de la que fue su rector; profesor emérito de las universidades de Trujillo, Piura, Cajamarca, Chiclayo, Cusco, Arequipa e Inca Garcilaso de la Vega en Perú; profesor clínico de neurocirugía de la Universidad de Miami y docente benemérito de la Universidad Mayor de San Marcos de Lima, a la que ingresó como estudiante en 1937, donde, a la vez, cursó Ciencias Biológicas. Además, fue miembro de la American Medical Association, del American College of Surgeons y uno de los iniciadores de la antropología médica en América Latina.

Médico neurocirujano por la Universidad de Pennsylvania, EE.UU., estudió e investigó con el doctor Karl Schmidt, descubridor de la efedrina. En 1950 incorporó en Perú los tratamientos quirúrgicos contra los aneurismas cerebrales y la epilepsia. Fundador de los Servicios de Neurocirugía del Instituto de Enfermedades Neoplásicas y de los hospitales del Niño, Loayza, Dos de Mayo, Militar, Naval y de Aeronáutica.

También fue director del Museo Peruano de Ciencias de Salud (1976-1990); fundador y primer director del Museo de la Nación (1988-1990), creador del Instituto de Medicina Tradicional del Ministerio de Salud de Perú. Este país -al que llegó a los 15 años- le concedió las Palmas Magisteriales en el grado de Amauta y el Premio Roussel (1988) por su ensayo Las plantas mágicas del Perú primigenio.

Su saber quedó plasmado en los libros Tronco encefálico (1957); La trepanación del cráneo en el antiguo Perú, en colaboración con Juan B. Lastres, fallecido a la publicación (1960);

1 Departamento de Español, Facultad de Educación y Humanidades, Universidad de Tarapacá, Casilla 6-D, Arica, Chile. pespinozac@uta.cl

2 Escuela de Artes Visuales, Vicerrectoría Académica, Universidad Austral de Chile, Casilla 567, Valdivia, Chile. paolalagos@uach.cl 
Los dioses vinieron del mar: ensayo etnohistórico (1972); Dioses y enfermedades: la medicina en el antiguo Perú (1974); La coca: dilema trágico (1992); La uña de gato y su entorno (1994); Apuntes de medicina tradicional: la racionalización de lo irracional (1993); Cien siglos de pan: 10.000 años de alimentación en el Perú (1995); La maca y la puna (1997) y Antropología del ají, entre otros, y más de 270 artículos y sus tesis de grado: (a) Bachiller en Medicina, 1946: El Sistema Nervioso Vegetativo Cardiovascular y la vida en las alturas, (b) Doctor en Ciencias Biológicas, mismo año: $L a$ acción antifatigante de la cocaína y la habituación a la coca en el Perú y (c) Doctor en Medicina, 1956: Fisiológica y clínica del tronco cerebral en las lesiones expansivas supratentoriales.

Digno de ser resaltado es que el Gobierno de Ucrania le confirió la "Medalla de Honor" por su contribución a la salud de las víctimas de Chernobil. Y, en 1979, fue tildado de 'brujo' y amonestado por las autoridades por defender sus principios: romper las barreras que separan la medicina oficial de la medicina tradicional. Aquí algunas de las reflexiones que el Dr. Fernando Cabieses Molina nos compartió.

\section{-Doctor, ¿hay un cambio de enfoque en la forma de comprender la medicina actual?}

-La medicina tradicional es común en todos los países del mundo, tal como la homeopatía es un buen enfoque. Todos los médicos que saben de medicina y la conocen la aceptan. Éstos (los médicos) aprueban que el 'naturismo' es una buena mirada, lo que no asumen es que un sujeto que no estudió agarre un libro y se ponga a curar. En otras palabras, lo que no tolera la medicina ni el Colegio Médico, es que alguien que le guste la homeopatía tome un texto y al año se ponga a curar gente. Eso está mal, porque no tiene la capacidad de conocer la anatomía, la fisiología, en qué puede hacer daño y en qué no.

Todos los países admiten que un médico graduado, que haya jurado, como en Chile, ponga su consulta y cure con naturismo. ...Lo que no aceptan las autoridades es que una persona que no tiene entrenamiento universitario agarre un libro, se consiga unas cuantas agujas y haga acupuntura. Sí un médico graduado que haya estudiado en China, dos o tres años, a su regreso trabaje acupuntura. Eso sí.

\section{-Don Fernando, ¿en América Latina hay un saber ancestral?}

-Sí, claro, y es el caso de Chile. Mire lo que pasa con los 'mapuche'. No me refiero a que usted sea nieto de mapuche, sino que tenga incorporada esa cultura. Sólo el $4 \%$ lo son, pero se puede vivir bajo el saber mapuche. Todos tenemos un $60 \%$ de cultura indígena y se debe aceptar que en ellos hay gente de buena fe dedicada a sanar.

Hay países biculturales, como Perú, con una geografía difícil, montañas muy elevadas, personas que viven sobre los 5.000 metros de altura, en poblaciones pequeñas. Si usted envía un médico, ¿qué hará éste allí? ¡Rebotar! Aunque le pague lo que le pague. .... No hay escuelas, ni laboratorios, menos farmacias. Los lugareños dicen, ¡qué viene hacer él acá! Las mujeres van a la partera, al curandero, y hay que aceptar esa realidad. Pero si a ese curandero se le ocurre venir a sanar a la ciudad, lo botan.

\section{- ¿Usted defiende la medicina tradicional?}

-Sí, claro. Siempre me preguntan si ésta es mejor que la moderna. En un principio, no podría decir que la medicina tradicional es mejor; sería lo mismo que afirmar que allá arriba, donde no hay automóvil, hay que ir a caballo. ...Es muy fácil entrar en discusiones infantiles, que fulano estaba desahuciado de cáncer, le dieron una hierba y se curó. ¿Cómo vamos a validar eso? No podemos. Cómo sabía la persona que el enfermo tenía cáncer.

\section{- ¿Cómo llegó a la medicina tradicional y cuántos años lleva en ella?}

-Trabajo en estas cosas desde 1955, alrededor de 40 años. Hay varias razones, pero fue suficiente mi interés por la historia. Empecé con la Historia de la Medicina de Arturo Pérez y muy pronto me di cuenta que la historia de la medicina del Perú no era suficiente para conocer sobre la medicina moderna.

...Cuando uno estudia la medicina te das cuenta que en el pueblito de al lado la hacen igualito como lo registra la historia. Hay que investigar sobre medicina con una historia viva y al estudiar la historia viva te das cuenta que hay todo un sistema de pensamiento llamado 'medicina tradicional'. Ésta se basa en las costumbres y tradiciones de los pueblos, en las creencias, en la cosmovisión, en el concepto de salud y enfermedad que ellos tienen; en la 'relación' médico-paciente tan diferente de los otros conocimientos. ...Al mismo tiempo, 
soy neurocirujano y sigo trabajando en la sala de operaciones. Cada intervención tiene que ser hecha en un hospital de alto prestigio científico, con instrumental sofisticado, con gente bien preparada, y eso cuesta. Entonces, la medicina en un pueblito con un hospital pobre es un gran mérito.

Mi vocación por ayudar a la gente se complementa estudiando cosas sencillas. No soy ni de izquierda ni de derecha, pero sí comprendo que todavía, a pesar que ya no hay izquierda ni derecha, hay arriba y abajo. Por eso tengo que pelear por los de abajo, de esos hay bastantes.

\section{-¿Qué mitos tiene la práctica de la medicina?}

-Casi todos los mitos tienen una racionalidad bastante clara, bien definida y relativamente estable. La gente cree que no cree. A modo de ejemplo, todos creemos en el mal de ojo..., en el mal, le llamamos diferente, pero todos creemos en él.

¿Saben qué es el susto? El sujeto se siente mal, los que tienen susto se enferman seriamente. También existe lo de las corrientes de aire, las personas afirman: ¡Le dio un aire!, pero los doctores no lo aceptan. Éstos dicen: ¡Nosotros no creemos en eso! El mal de ojo es una enfermedad muy antigua y consiste, supuestamente, en que el ojo, que es un aparato receptor, se convierte en un órgano proyector, o sea, arroja una mirada aletargadora. Como el gorila que trata de defender su territorio cuando algún jovencito quiere enamorar a sus hembras, si el otro sigue avanzado éste le cae encima. Uno ofrece una mirada encantadora y, el otro, una de violencia.

\section{...-¿Lo mismo ocurre con el susto?}

-Con el susto pasa lo mismo. ¿Qué le pasó?, se asustó, por eso está enfermo. Si lo dicen así, se ve como una superstición tonta; pero si el médico afirma: "está con stress", ahí sí lo entiendes. Es un problema de semántica. Hay que usar la palabra correcta, pero en el fondo es lo mismo. Mucho de lo que uno piensa son supersticiones que no tienen importancia, son diferentes puntos de vista, de vocablos, de mecanismos. Supuestos y nada más.

Que venga un médico a explicarme cómo funciona el stress, eso tiene tanta dificultad como cuando un curandero me quiere aclarar qué es el susto. Sabemos que es la reacción ante una situación posiblemente amenazante, que se suma a la resistencia de la madre. Ésta se asusta y comunica su ansiedad al niño, pero cuando lo lleva a un curandero éste lo tranquiliza y, por lo tanto, la mamá también se aquieta. El hijo y la madre se calman. Esto funciona dentro de la estructura mente-cuerpo que conocemos.

\section{-Doctor, en otra línea, ¿cómo explica el fenómeno de los duendes?}

-Eso se originó en Europa. Allá hay una planta, que me dicen que también está acá, en el Jardín Botánico de la Universidad Austral de Chile. Es un hongo rojo, luminoso, con pintas blancas. Se comen los alcaloides presentes en él. Se usa en los ritos siberianos y lapones del norte de Europa. Si lo comes, todo se achica y la gente que te rodea se ve como enanitos. Se asocia a los enanitos con el hongo, las cosas que vuelan, las hadas y los duendes, entre otros. Todo eso tiene un origen muy claro, no son invenciones, pero hay que buscar cuál es el comienzo para poder estudiarlo.

De ahí salen los cuentos de niños. La bruja que le da la manzana 'envenenada' a Blanca Nieves, ésta se queda dormida, ve enanitos y un montón de cosas más. Todo revela que en algún momento a una muchacha le dieron el hongo, que tuvo ese sueño y lo contó. Se despertó con el beso de un príncipe, fue un sueño erótico; dicen que en vez de un beso habría sido otra cosa, quizás. Tal vez, la bruja fue pagada por alguien que quería seducir a la muchacha. De ahí vienen los cuentos y se adaptan a la inocencia del niño, al puritanismo de la gente que escucha.

\section{-¿Qué pasa con la gente que dice ver este tipo de figuritas?}

-En realidad, son ritos. Mucha gente lo come, se intoxica, se siente mal y ve distorsiones. Parece ser que el verdadero rito está en el 'Gran Chamán', él lo ingiere y no se intoxica. Pero en él se metabolizan los venenos, todas estas sustancias. Eso sí, hay dos, el 'muscimol' y la 'muscarina', que son eliminadas íntegras por el riñón. El rito consiste en que el Chamán las come y a las dos horas orina, para luego beberla. Al hacerlo, químicamente incorpora 'muscarona' y ahí tiene las consecuencias.

...Se habla de la relación que existe entre una cosa y otra, pero a la hora que lo van a probar te falta esa pieza en el mosaico, un rompecabezas que no lo llegas a entender.

-En Chile se consumen alucinógenos potentes como el chamico y el floripondio, ¿por 
qué no ocurre el mismo efecto, como ver esos 'hombrecitos'?

-Cada alucinógeno causa resultados diferentes. Algunos provocan necrosis, otros sonidos especiales, sensación de vuelo, un sentido de falta de peso, la percepción que el tiempo corre muy lento, como con la marihuana. Ésta te da una alucinación del reloj biológico. Cada uno de nosotros tiene una interpretación del tiempo; generalmente, las personas bien disciplinadas y civilizadas lo sabemos. Como ejemplo, me programo: ¡voy a ir a la universidad y regreso!, ;en 20 minutos estoy de vuelta! Hay gente que no tiene la menor idea. Ese reloj biológico, a veces, puede cambiar con algunos tipos de drogas, como con el 'cumarinol' (anticoagulante). El que fuma marihuana bien fumada se mueve muy rápido, porque cree que todo va lento, quiere parecer normal y está acelerado. No todos los alucinógenos producen lo mismo.

Una de las primeras etapas de ellos es que los aparatos receptores: la vista, el olfato, el gusto, los sentidos en general, se descompletan y se mezclan. Por ejemplo: una música que tiene 'un color precioso', música con color, o 'un color que es una melodía'. Eso pasa porque las neuronas, que normalmente están separadas, se tienden a juntar; es lo que llamo 'antropología neurológica', como soy neurólogo y antropólogo lo nombro de esta manera: "el estudio antropológico de los trastornos neurológicos producidos por diversos ritos".

\section{-¿Lo mismo ocurre con el ritmo?}

-El ritmo está en todos los ritos. No te parece cosa más idiota que cuando tu equipo favorito mete un gol te 'arrancas' a aplaudir, ¡qué cosa más idiota! ¿Por qué tienes que hacer eso? Porque el ritmo te sirve para descargar. Está en todas las actitudes físicas.

También el canto, que está en todas las religiones. Cantan porque el canto encanta, de ahí viene la palabra encantar. Te lleva a un estado de encantamiento místico, por eso todas las religiones cantan, todas tienen música. La música se inicia con la religión. Todos los chamanes del mundo usan un tambor o una maraca para entrar en ritmo. El ritmo también es un problema neurológico y antropológico.

\section{- ¿Se ocupan alucinógenos en las prácticas de la medicina en los indígenas de Perú?}

-Los indígenas del Perú usan alucinógenos para curar enfermedades, pero no para tratar una fractura de húmero; tampoco sirve para una tifoidea. Eso sí, tienes que tener en cuenta que más de la mitad, diría el $80 \%$, de las enfermedades comunes tienen un origen emocional. Reaccionas con una diarrea ante una situación desagradable, las emociones las producen. Todas esas reacciones neuronales funcionan independientes de las emociones; son influenciadas por ellas y muchas enfermedades se producen por éstas. No hay enfermedad que no esté acompañada por una emoción. Al individuo que le duele una muela está desesperado, tiene una emoción terrible, no sabe si va a poder ir a trabajar; segundo, porque le duele; tercero, se siente solo y ahí empieza a pensar en sus problemas. Y todo por una enfermedad idiota: una muela 'picada'.

La parte emocional de todas las enfermedades es muy importante y es la que tratan los chamanes, especialmente los del desierto nortino del Perú y los de la selva amazónica. Éstos tratan con alucinógenos, en pequeñísimas dosis, porque le permite penetrar en el subconsciente de su paciente, tranquilizarlo con palabras y con una música especial. Eso es neurología y antropología a la vez.

\section{-Don Fernando, ¿en estos tiempos se generan nuevos chamanes?}

-Tiende a desaparecer. Hay una urbanización caótica de la población peruana. Todos los muchachos jóvenes están yéndose a la ciudad a buscar fortuna, consideran que ésta les ofrece muchas cosas. Es como el mapuche que va a Santiago a buscar chamba (trabajo). Los chamanes vienen con los suyos a las urbes.

También el terrorismo ha producido una cosa dolorosa. Sendero Luminoso ha despoblado el área rural, la gente se refugia en las ciudades y un chamán ahí no funciona bien, porque no tiene el manejo de una comunidad de cien familias. En ésta el chamán, consciente e inconscientemente, tiene una gran cantidad de información. Lo que no sabe informado lo ve, lo adivina. Se dice adivina, porque el hombre primitivo cree que es una 'cosa divina', entonces, predicen el futuro. Predecir el futuro es la base de la ciencia y la ciencia es predecir el futuro. Los médicos, los contadores, los petroleros, todos predicen. El que no sabe cómo se hace cree que está adivinando.

-Respecto de los chamanes o de los indígenas en general, ¿con la llegada de los europeos a 
América se produce esa fusión, esa mezcla en sus 'prácticas médicas'?

-Hay un problema con la conquista. Uno trata de ver lo que pasó en ese tiempo y juzgar a las personas que formaron parte de esa escena con estándares actuales. Te pones a estudiar los derechos humanos en ese tiempo y te mueres de hambre, ¡qué derechos humanos! No puedes decir que eran unos desgraciados; todo es según el color del cristal con que miras. Los españoles llegados a América eran muy guerrilleros, venían de botar a los árabes con la cruz y la espada. Sus abuelos habían estado en las cruzadas luchando por recuperar de los turcos la posesión. Todo era religión para ellos.

Otra cosa, la medicina de éstos era religiosa, no la de Hipócrates y Galeno. Eso había sido descartado completamente. Cuando la iglesia se metió en Roma y en el mundo civilizado de entonces excluyeron toda la 'medicina pagana' por pagana. Ésta se metió en los conventos y así surgió la medicina monástica..., puramente religiosa. Los hospitales estaban al lado de las iglesias, para entrar a ellos tenías que confesarte, comulgar y arrepentirte. Así Dios te iba a ayudar y, si no lo hacía, menos mal, te ibas directo al cielo. En eso consistía la medicina. Estaba estrictamente unida a la religión, a un pueblo conquistador fregado que no veía sino espadas y la cruz. Era la imposición de su religión y, a través de ésta, su medicina.

\section{- ¿Había que destruir las creencias locales?}

-Sí, claro. Había que destruir la religión y la medicina de acá, pues era obra del diablo, según ellos. Hubo un encontrón sanguinario y doloroso, pero no los juzguemos con nuestras ideas, sino con las de ese tiempo.

En esa época el apóstol Santiago no se llamaba Santiago, era Jaco, viene del inglés. Para ellos no hay Santiago, existe Jack, de Jaco. Los judíos lo nombran Jaco, no Santiago. Santiago viene de 'San te hago', 'te hago Santo', y eso lo unieron con San Jago; de ahí Santiago Mata Moros. 'San te hago' que mata moros, todo mezclado. Hay que entenderlo así, porque si tratas de comprenderlo con tus criterios actuales te vas al 'canasto', no entiendes nada y empiezas a decir: ¡qué hijos de puta!, cómo destruyeron los templos. Claro que lo hicieron, ¿acaso los cristianos no destruyeron los templos paganos?, ¿no descabezaron todas las estatuas de la pobre Venus de Milo? Se decapitaron cristianos y le quitaron los brazos. Los iconoclastas son los destructores de imágenes, porque acabaron con la idolatría de los paganos y vinieron aquí a destruir la idolatría de los Incas, de los Aztecas, de todos.

\section{-En esta línea, ¿cómo sobrevivieron los chamanes a esta guerra?}

-En esta guerra los chamanes, que se las sabían todas, se escondieron. Además, sus rezos, que si bien eran los de los cristianos, en realidad hablaban de sus dioses. Los disfrazaron. A la ceremonia le pusieron la mesa del curandero. Misa es mesa, porque la 'i' y la 'e' son iguales en estos idiomas, entonces, la mesa es la misa que ellos hacen. Todo está disfrazado.

\section{-...¿Este traspaso cultural-religioso desde los europeos a los indígenas fue azaroso?}

-Hay que tener en cuenta que estaban en el siglo XVI. Si lees la historia de Chile te preguntas, ¿qué estaría pasando en Europa en esa época? Allá hubo la extinción del anticristo, del demonio. Éste casi no existía en la religión. El demonio fue parte de una lucha subterránea en contra del cristianismo. ¿De dónde salieron las brujas y la adoración al diablo? Todo lo que iba en contra de Cristo era bueno. Ahí surgió una serie de supersticiones que aún existen: que el viernes es 'día de brujas', porque ese día mataron a Cristo, entonces, hay que celebrarlo y ocupar el vacío. Éstas hacen su aquelarre los viernes. También puedes considerar que el trece es un mal número, porque los apóstoles eran doce y Cristo; a uno lo mataron y uno se suicidó. Pero los brujos afirman: el trece es buena suerte, porque mataron a Cristo. Esto provocó que asesinaran alrededor de un millón de personas en una hoguera, para combatir la brujería, para ir en contra de la adoración del diablo.

Otra cosa, ¿por qué para decir algo malo nombran cabrón? Porque el diablo está personificado como un 'cabro negro' o como un toro, o sea, Satanás es un cabrón. De ahí vienen todas esas cosas. Si te pones a ver por qué decimos lo que decimos y por qué lo utilizamos, te das cuenta que todas las cosas son de las religiones.

\section{-...¿En la medicina tradicional la relación con el paciente es diferente?}

-Esa relación consiste en entender bien que hay tres elementos en una persona enferma: (a) necesita que lo curen; (b) necesita que lo cuiden, y cuidar significa cariño, algo más humano, y 
(c) el paciente debe sentir deseos de sanarse, no tirarse a muerto. ...Al paciente hay que hablarle para que tenga ganas de recuperarse.

\section{-Mi pregunta apuntaba a los indígenas y a su cosmovisión.}

-El curandero tiene mucho de eso, cuida mucho. Hay cosas muy sencillas. Ponte en el caso de que roban tu automóvil, me lo cuentas y te digo: anda a la comisaría, pon la denuncia y explícale a la policía. Otra cosa es exclamar: ¡diablos!, y tocar a la persona afectada. Ese tocar es cuidar, es comunicarse. Una cosa es curar y otra es cuidar, es diferente.

Una partera que va a la casa de la parturienta se ocupa de todo, hasta de cocinar. El ginecólogo dice que lo llamen cuando la mujer esté dilatada. Son formas de ver la vida y de entender el concepto 'salud'. Los criterios de bueno y malo o sano y enfermo varían con la cultura. Cambian las cosas sin que uno diga qué barbaridad, cómo hicieron eso; nuestros criterios actuales son muy diferentes.

Tantos buenos hombres que estuvieron involucrados en la inquisición, no es que fuesen hombres crueles, eran las reglas del juego. No es bueno juzgar así a hombres de otras épocas y culturas. Una vez defendí a uno de los jefes de una comunidad indígena integrada por unas 60 personas. El hijo de éste violó a una muchacha; el papá le dio, le dio, le dio y le dio..., lo 'apaleó' fuerte. Como a las tres semanas volvió a violar, él fue y lo mató. Vino la justicia a meterlo preso y toda la comunidad lo defendió. Lo tuvieron que soltar. Ésta (la comunidad) dijo que, de acuerdo a sus leyes, el hombre había hecho bien.

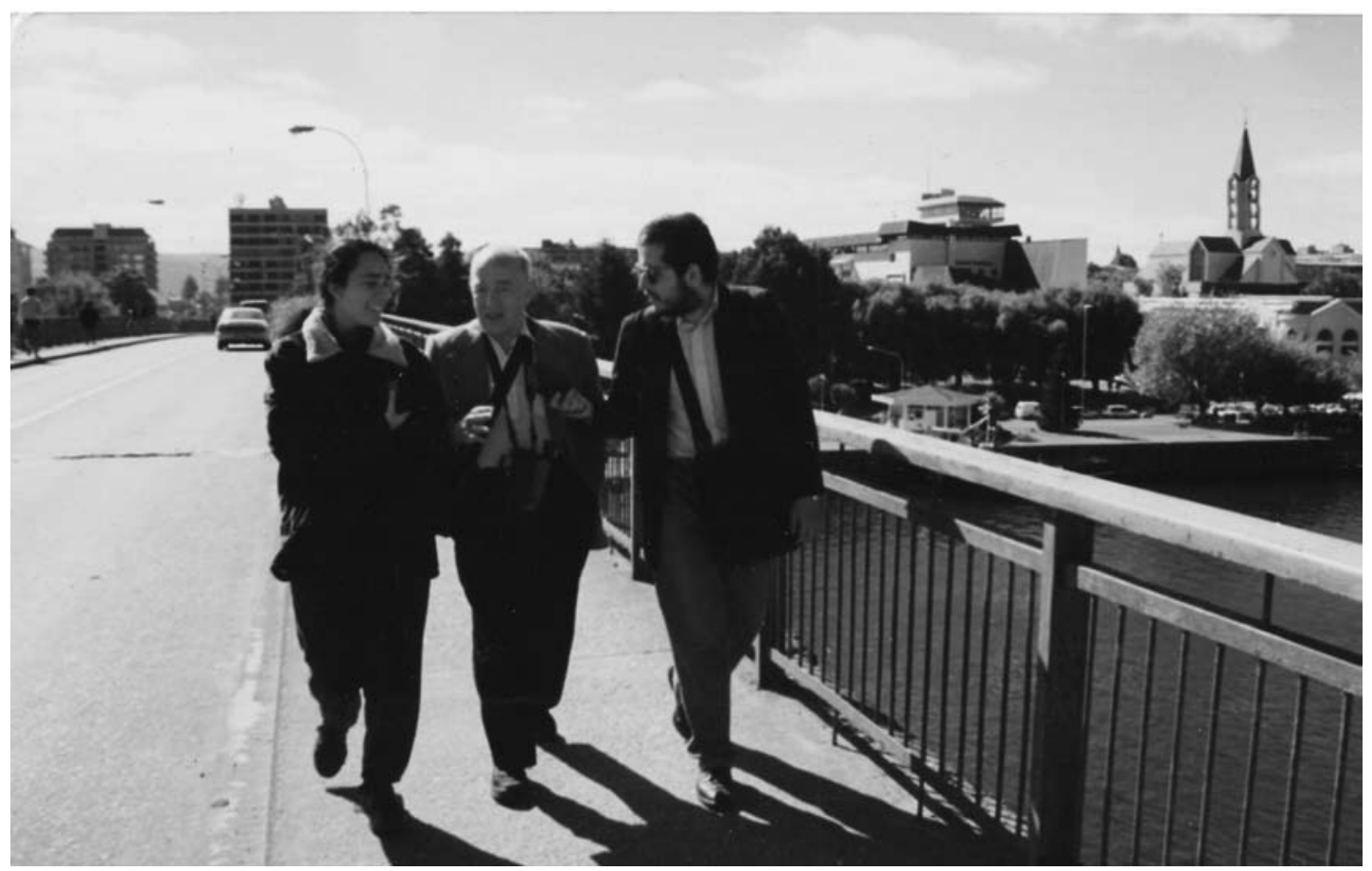

Paola Lagos Labbé, el Dr. Fernando Cabieses Molina (Q.E.P.D.) y Pablo Espinoza Concha, cruzan el puente Pedro de Valdivia hacia la Isla Teja, Valdivia, Región de Los Lagos, Chile. 